\title{
ELEMENTOS RETÓRICOS EN LOS SENATVS CONSVLTA DE GERMÁNICO CÉSAR Y DE GNEO PISÓN
}

\begin{abstract}
ÁLVARO SÁNCHEZ-OSTIZ
Universidad de Navarra

Este artículo analiza tres pasajes capitales de los senatus consulta relativos a los honores póstumos concedidos a Germánico César (Tabula Siarensis) y al juicio de Pisón (Senatus Consultum de Gnaeo Pisone Patre), en los que se halla reflejada la elaboración retórica de los discursos senatoriales originales: 1. el decreto inscrito en el arco en el Circus Flaminius (TS I 9-18); 2. la alabanza por parte del senado de la moderatio de la casa imperial en los días que siguieron a la muerte de Germánico (SCPP 123-151); y 3. el decreto acerca de los retratos de Germánico y Druso en la biblioteca del Palatino (TS IIc 13-17). El notable uso de la oratoria epidíctica en estos discursos deliberativos y judiciales no es accidental, sino intencionada: muestra cómo la ideología política del Principado influye en la práctica de la retórica.

This paper analyses three principal passages of the senatus consulta about the posthumous honours for Germanicus Caesar (Tabula Siarensis) and about Piso's trial (Senatus Consultum de Gnaeo Pisone Patre), in which the rhetorical elaboration of the original senatorial discourses are reflected: 1 . the decree on the arch at the Circus Flaminius (TS I 9$18)$; 2. the praise by the senate of the imperial house's moderatio during the aftermath of Germanicus' death (SCPP 123-151), and 3. the decree on the portraits of Germanicus and Drusus in the library on the Palatine (TS IIc 13-17). The remarkable use of epideictic oratory in these deliberative and judicial discourses is not accidental but intentional. It shows how the political ideology of the Principate influences the rhetorical practice.
\end{abstract}

\section{Introducción}

La elaboración retórica de las propuestas senatoriales que dieron lugar a los senadoconsultos de Germánico César en el 19 d.C. y de Gneo Pisón en el 20 d.C. ${ }^{1}$ no pasó desapercibida a Tácito, quien comenta ambiguamente el modo

1 Los ediciones utilizadas han sido A. Sánchez-Ostiz, Tabula Siarensis: edición, traducción y comentario, Pamplona, 1999 y A. Caballos, W. Eck y F. Fernández, El Senatus Consultum de Gneo Pisone Patre, Sevilla, 1997 (W. Eck, A. Caballos y F. Fernández, Das senatus consultum de Cn. Pisone Patre, Múnich, 1996). Desde ahora, TS = Tabula Siarenis; SCPP = Senatus 
de elección de honores póstumos y las intervenciones en las sesiones del proceso penal ${ }^{2}$. De las sentencias pronunciadas hasta la formulación definitiva en el documento publicado media una reelaboración, que no modificaría sustancialmente el tono y el propósito originales.

Es por tanto normal que, a pesar de hallarse al final de la cadena de composición, ambos documentos muestren una relación de "architextualidad" con pautas de la preceptiva oratoria. Sin embargo, no está tan claro que las sentencias buscaran además una relación de "intertextualidad" con modelos retóricos concretos. Si bien a lo largo de estos casi veinte años de investigación desde la aparición de la Siarensis, se han destacado los paralelos de estos dos textos jurídicos con otros testimonios epigráficos y literarios, no se ha prestado suficiente interés a las connotaciones que estas relaciones intertextuales hayan podido sugerir.

Por otra parte, dada la singular unanimidad que domina en las sesiones senatoriales, apenas hay diferencia entre lo propuesto y lo aprobado, lo cual es parte del llamativo tono encomiástico de los decretos, acorde con la finalidad propagandística que denota la extensiva publicación en las provincias ${ }^{3}$. Sin embargo, este recurso al género laudatorio es paradójico, si se considera estrictamente en el marco de la llamada "división aristotélica" de los géneros. En un principio, el senadoconsulto de diciembre del año 19 utilizaría modos retóricos deliberativos para determinar la pertinencia de cada una de las propuestas, mientras que en el caso del proceso de Pisón el género sería más bien judicial. No obstante, es inadecuado considerar que estos dos textos epigráficos son meramente piezas de oratoria demostrativa. La propia tradición retórica considera que el tercer genus sea auxiliar de los otros dos, lo que

\footnotetext{
consultum de Cn. Pisone Patre.

2 Ann. II 83.1: honores, ut quis amore in Germanicum aut ingenio ualidus, reperti decretique (ingenio ualidus ironiza la adulación a través de la inventiva, necesariamente considerada habilidad retórica y III 13.2: Seruaeus et Veranius et Vitellius consimili studio et multa eloquentia Vitellius obiecere odio Germanici et rerum nouarum studio Pisonem uulgus militum per licentiam et sociorum iniurias eo usque conrupisse ut parens legionum a deterrimis appellaretur.

3 W.D. Lebek, «Die zwei Ehrenbeschlüsse für Germanicus und einer der 'seltsamten Schnitzer' des Tacitus (Ann. 2,83,2)», ZPE 90, 1992, pp. 66ss. Los modos del lenguaje adulatorio en gran medida son creación de la clase senatorial: F. Millar, «Ovid and the domus Augusta», JRS 83, 1993, p. 3ss. Vid. asimismo G. Calboli, «The S. C. de Cn. Pisone patre: Asianism and Juridical Language», en Papers on Rhetoric III, ed. L. Calboli Montefusco, Bolonia 1990, pp. 1-26.
} 
explicaría el marcado acento eulogístico de estos textos legales. Desde esta perspectiva, me propongo analizar cómo se reflejan en estas dos inscripciones rasgos de la técnica retórica de la que los senadores se sirvieron al presentar sus propuestas. Sobre esta base quiero además apuntar que la intervención de modos, tópicos y recursos propios del genus demonstratiuum no es meramente auxiliar o accidental ${ }^{4}$, sino que responde a una profunda conexión del ideario político del principado con un problema de definición de los géneros.

\section{Los senadoconsultos y la tradición retórica}

Los documentos, elaborados por medio de la adición de las diferentes sententiae, pueden incidir reiteradamente sobre unidades temáticas, que caracterizan a su vez a los miembros de la familia Julio-Claudia y a Pisón, a través de referencias a sus virtudes o vicios y a través de la relación de sus hazañas o crímenes. Tres de estos aspectos son objeto de un análisis más detenido: las res gestae de Germánico, la temperantia de la familia JulioClaudia y la educación ejemplar del joven César.

\subsection{Fortitudo Germanici}

Las hazañas bélicas de Germánico desempeñan en estos documentos un papel principal, si bien no dominante: su uirtus guerrera se destaca indirectamente en relación con la laudatio que hizo Tiberio en el senado (TS IIb 14-15: ... Germanici Caesaris f(ili) eius non magis laudatio/nem quam uitae totius ordinem et uirtut ${ }^{\lceil}$is $\rceil$eius uerum testimonium contineret); y asimismo en la narración de los sucesos de Siria, que pone de relieve el contraste de su actuación con la de Pisón (SCPP 23-70).

Sin embargo, el decreto de erección de un arco en el Circo Flaminio (TS I 9-18) tematiza expresamente la fortitudo Germanici en el titulus que se habrá de colocar en la parte frontal del monumento y que recoge la relación de sus hazañas: su actuación en el Rin - focalizada en los signa recepta y la venganza

\footnotetext{
4 Tac. Ann. II 82.3 podría ser prueba de que en las sesiones del senado hubo verdadera deliberación. En la decisión acerca de las honras fúnebres, se habría ido demasiado lejos y Tiberio se habría opuesto a la propuesta de colocar un retrato de Germánico entre los literatos. Resultaría contradictorio dentro de un contexto epidíctico que el princeps desestimara una de las proposiciones. Como se comentará más adelante, la unanimidad resaltada por la propaganda previene de considerar auténtica esta apariencia de deliberación.
} 
del desastre de Varo -, en la Galia y la misión en Oriente, durante la cual, a modo de culmen heroico de su vida, había muerto por la patria.

El hecho de que Germánico pereciera en acto de servicio - ob rem p(ublicam) obisset - es el núcleo de la propaganda de lenguaje y de imágenes transmitida a través del arco romano. La fraseología no es nueva y alude inequívocamente al universo de imágenes de la República ${ }^{5}$. Éste se hacía visualmente presente en el espacio romano gracias a los retratos de los grandes personajes que habían actuado ejemplarmente en nombre e interés de la patria. Esta monumentalización concentra la historia de Roma en las res gestae de las familias, cuyos protagonistas se convierten en exempla para toda la comunidad.

En el plano de la formulación de la propuesta en el senado, quien pronuncia el discurso se sirve de una tradición retórica acerca de la "muerte por la patria", que está fijada en los exempla, se halla recogida en la preceptiva y encuentra realización en géneros laudatorios y consolatorios ${ }^{6}$. Se produce, por tanto, una relación de architextualidad respecto a un género y a un modelo temático tradicional. Además de ésta, se recurre a otra relación de trascendencia textual con un modelo generacional. En el debate político del final de la República y del primer Principado, los discursos ciceronianos adquieren una naturaleza ejemplar, que deja su impronta en los textos legales, gracias a la imitatio llevada a cabo por las intervenciones particulares ${ }^{7}$; en TS I 9-18 en particular, el modelo elegido es la novena Filípica. Los paralelos de lenguaje y estructura señalan, sin embargo, que este discurso ciceroniano no es sólo un modelo técnico, sino que sirve además para evocar en el auditorio connotaciones acordes con el debate político del momento.

$5 \quad$ M. Stemmler, «Auctoritas exempli. Zur Wechselwirkung von kanonisierten Vergangenheitsbildern und gesellschaftlicher Gegenwart in der spätrepublikanischen Rhetorik», en B. Linke y M. Stemmler (eds.), Mos maiorum. Untersuchungen zu den Formen der Identitätsstiftung und Stabilisierung in der römischen Republik, Stuttgart, 2000, p. 141ss.

6 Sobre el motivo de la muerte por la patria en la preceptiva y en la literatura augústea, v. los testimonios que ya aduje en «Periit dux pro patria: consuelo, encomio y epitafio en el Epicedion de morte Drusi», en C. Alonso del Real (ed.), Consolatio. Nueve estudios, Pamplona, 2001, pp. 117-134.

7 Como indican, por ejemplo, los paralelos con las Verrinas en la Ley Gabiria Calpurnia del año 58: C. Nicolet, «Lexicographie politique et histoire romaine: Problèmes de méthode et directions de recherches», en I. Lana y N. Marinone (eds.), Atti del convegno sulla lessicografia politica e giuridica nel campo delle scienze dell'antichità, Turín, 1980, p. 26ss. y M. Crawford (ed.), Roman Statutes, Londres, 1996, p. 22. 
Cic., Phil. 9 es pronunciado en febrero del 43 a.C., durante el debate que dirime los honores de Servio Sulpicio, fallecido durante la misión en la que había de presentar a Antonio las exigencias del senado. El género es deliberativo, pero participa de rasgos propios de la laudatio póstuma y de las consolationes. Una comparación detenida con TS I 9-18 ilustra la intención del senado. El texto de este decreto sería el siguiente (las correspondencias entre ambos textos se señalan mediante superíndices $)^{8}$ :

${ }^{\mathrm{s} 0}$ Placere uti íanus marmoreus extrueretur in circo Flaminio ${ }^{\mathrm{T} 3} \mathrm{pe}[\mathrm{cunia}$ publica, posi]/tůs ad eum locum, in quo statuae diuo Augusto domuique Augus[tae publice positae es]/sent ab G(aio) Norbano Flacco, cum signis deuictarum gentium in a[ngulis ${ }^{\mathrm{S} 1}$ tituloque] / in fronte eius íani senatum populumque Romanum id monum[entum aeternae dedi]/casse memoriae Germanicí Caesaris, ${ }^{\mathrm{S} 2}$ cum i $\{1$ í s Germanís bello superatis et[ deinceps] / a Gallia summotis receptísque signis militaribus et uindicata fraud[ulenta clade]/ ${ }^{15}$ exercítus p(opuli) R(omani), ordinato statu Galliarum, ${ }^{\mathrm{T} 1 \mathrm{~b}}$ proco(n)s(ul) missus in transmarinas pro[uincias]/ in conformandís iís regnisque eiusdem tractus ${ }^{\mathrm{T} 1 \mathrm{a}}$ ex mandatís Ti(berii) $\mathrm{C}^{\lceil} \mathrm{a}^{\top}$ esaris $\mathrm{Au}\left[\mathrm{g}(\right.$ usti), dato re $] / \mathrm{g}^{\lceil} \mathrm{e}^{\top}$ Armeniae, non parcens labori suo, priusquam decreto senatus [ouans urbem ingre]/deretur, ${ }^{\text {S3 }}{ }^{\text {(T2) }}$ ob rem $\mathrm{p}$ (ublicam) mortem obisset.

Parecía bien que se construyera un arco de mármol en el circo Flaminio con dinero [público, colocado] junto al lugar en el que habían [sido colocadas públicamente] estatuas en honor del divino Augusto y de la domus Augusta por Gayo Norbano Flaco, con enseñas de los pueblos vencidos en los [ángulos y con una inscripción] en la parte frontal de este arco que diga que el senado y el pueblo romano habían dedicado este monumento [al eterno] recuerdo de Germánico César, porque, una vez vencidos los germanos en la guerra y expulsados [más tarde] de la Galia, tras la recuperación de las enseñas militares y de la venganza por la traicionera [derrota] del ejército del pueblo romano, una vez regulada la situación de las Galias, siendo él procónsul enviado a [las provincias] de ultramar para aquietar éstas y los reinos de esta zona, después de haber [dado] un rey a Armenia conforme a la misión encargada por Tiberio César Augusto, sin cejar en su empeño, antes de entrar victorioso en la ciudad por decreto del senado, había muerto por la patria.

La estructura de la sententia ${ }^{9}$ en Cic., Phil. 9.15 se asemeja en tono y propósito al texto bético:

Quas ob res ita censeo: ${ }^{\mathrm{S} 1} \mathrm{Cum}$ Ser. Sulpicius Q. f. Lemonia Rufus difficillimo rei publicae tempore, graui periculosoque morbo adfectus, auctoritatem senatus, ${ }^{\mathrm{Tla}}$ salutem rei publicae uitae suae praeposuerit contraque uim grauitatemque morbi contenderit, ut in castra $\mathrm{M}$. Antoni quo senatus eum ${ }^{\mathrm{Tlb}}$ miserat perueniret, isque, cum iam prope castra uenisset, ui morbi oppressus uitam amiserit ${ }^{\text {T1a }}$ maximo rei publicae tempore, eiusque mors consentanea uitae fuerit sanctissime honestissimeque actae in qua saepe magno usui

8 V. el aparato crítico y el comentario en Tabula Siarenis (n. 1), pp. 52-54 y 104-132.

9 A saber: oración causal introductoria con cum + senatui placere + propuestas (AcI+ uti...). 
rei publicae Ser. Sulpicius et priuatus et in magistratibus fuerit: (16) ${ }^{\mathrm{S} 1}$ cum talis uir ${ }^{\mathrm{T} 2} \mathrm{ob}$ rem publicam in legatione mortem obierit, ${ }^{\text {s1 }}$ senatui placere Ser. Sulpicio statuam pedestrem aeneam in rostris ${ }^{\mathrm{S} 0} \mathrm{ex}$ huius ordinis sententia statui, circumque eam statuam locum ludis gladiatoribusque liberos posterosque eius quoquo uersus pedes quinque habere, ${ }^{\mathrm{s} 2}$ eamque causam in basi inscribi quod ${ }^{\mathrm{S} 3}$ is ob rem publicam mortem obierit, utique C. Pansa A. Hirtius consules, alter amboue, si eis uideatur, quaestoribus urbanis imperent ut eam basim statuamque faciendam et in rostris statuendam locent, quantique locauerint, ${ }^{\mathrm{T} 3}$ tantam pecuniam redemptori attribuendam soluendamque curent ...»

En ambos casos, se habla de un momento grave para la res publica que exige una intervención (T1a), por lo que se envía a alguien en misión hacia Oriente (T1b) ${ }^{10}$. Durante la misión el enviado de Roma enferma y fallece, lo que se considera una muerte por la patria (T2). En ambos casos se da en este punto un salto lógico, puesto que este tipo de honor público se ha referido hasta entonces sólo a los muertos en la batalla; Cicerón, lo salva con la argumentación de los capítulos 3-7 ${ }^{11}$. Por su parte, el tono encomiástico de la tabula Siarensis no encuentra problema en ello. La estructura de la propuesta senatorial es la siguiente: el senado decide o ha de decidir (S0), tomando como motivo el hecho de su muerte heroica, expuesta en una cláusula causal (S1), que se erija un monumento a la memoria del caído con una inscripción (S2), la cual ha de inmortalizar el que haya fallecido en acto de servicio (S3); por último se recuerda que el honor será público (T3). La principal diferencia estructural entre ambos testimonios estriba en que la cláusula causal es anterior y queda fuera del texto de la inscripción en la sentencia de la Filípica 9, mientras que en el senadoconsulto del año 19 d.C. es la propia cláusula el texto de la inscripción junto con una referencia a la memoria de Germánico.

A la vista de los paralelos, quien construyó retóricamente la sentencia del arco romano de Germánico se sirvió deliberadamente de la novena Filípica. No sólo se trata de que de la única coincidencia de la expresión de TS I 18 se encuentre en Phil. 9.16 ( ob rem publicam mortem obierit), sino de una íntima conexión de estructura. Con ello - tal como la estatua de Sulpicio Rufo era un

10 La idea de la misión y del momento político crítico está también en $S C P P$ 30-31: ... Germanico Caesari, qui a principe nostro ex auctoritate huius ordinis ad / rerum transmarinarum statum componendum missus esset.

11 El nudo argumentativo es que Sulpicio ha muerto como legado y por la patria (cap. 3); como otros exempla ad casum que tienen una estatua en el foro (caps. 4-5); la causa de la muerte ha sido el propio senado (cap. 6); pero el culpable ha sido Antonio, hecho que debe ser mencionado en la estatua de Sulpicio (cap. 7). 
memorial y a la vez un medio de propaganda contra Antonio - se quería apuntar connotativamente que Germánico había muerto en el transcurso de una misión de vital importancia para la res publica, que asumió en un acto de valor; que la causa de la muerte había sido un enemigo de la patria y que el senado guardaba una deuda de gratitud hacia él ${ }^{12}$.

En el contexto de la misión in transmarinas prouincias de Germánico el paralelo Antonio-Pisón aparece cargado de significado. La comparación tiene lugar mucho antes del proceso penal contra Pisón y por tanto antes de que llegue a manos de Tiberio el libelo en el que el acusado exponía sus quejas de Germánico $^{13}$. Sin embargo, Pisón había recriminado al joven princeps de infracción del mos maiorum de ostentación de lujo e incluso de traición a la patria ya antes de su muerte, principalmente explotando la comparación con el tipo propagandístico del Alejandro-Antonio ${ }^{14}$. Después de la muerte de Germánico, bien la propaganda oficial, bien la llamada "facción germanicana"15 llevan a cabo una retorsio de los mismos argumentos pisonianos, que cunde en la opinión pública y que se ve reflejada tanto en la tabula Siarensis como en el senadoconsulto de Pisón. En éste se observan alusiones ocasionales que se remiten a la Filípica 9 - sin una estrecha relación entre dos sentencias como en el caso de TS I 9-19 - y que inciden sobre la fortitudo-patientia Germanici ante los scelera Pisonis con el telón de fondo de las guerras civiles ${ }^{16}$.

12 Sobre el papel de la propuesta ciceroniana en el marco del debate político en los años 4431 a.C., M. Sehlmeyer, Stadtrömische Ehrenstatuen der republikanischen Zeit, Stuttgart, 1999, p. 252ss. El modelo generacional o de escuela elegido debe corresponder necesariamente a las características del discurso que lo toma como referente: W. Stroh, Taxis und Taktik, Stuttgart, 1975, p. 52ss.

13 Tac. Ann. II 78.1 y SCPP 58-61.

14 Tac. Ann. II 57 y II 78: las acusaciones rememoran la propaganda antiantoniana antes de Accio, cfr. G. Cresci Marrone, «Germanico e l'imitatio Alexandri in Oriente», en G. Bonamente y M.P. Segoloni (eds.), Germanico. La Persona, la Personalità, il Personaggio nel bimillenario dalla nascita, Roma, 1987, p. 67ss.

15 B. Gallotta, Germanico, Roma, 1987, p. 161ss. y M. Pani, «La missione de Germanico in Oriente: politica estera e politica interna», en G. Bonamente y M.P. Segoloni (eds.), Germanico. La Persona, la Personalità, il Personaggio nel bimillenario dalla nascita, Roma, 1987, p. $1 \mathrm{ss.}$

16 V. SCPP 27-29: atq(ue) ob id morientem Germanicum Cae/sarem, cuius mortis fuisse caussam Cn. Pisonem patrem ipse testatus sit, non inme/rito amicitiamei renuntiasse. Germánico renuncia a la amistad de Pisón, obligado por la actitud de éste, que es presentado como verdadera causa de la muerte del legado (sobre la patientia como parte de la fortitudo, junto con la magnificentia, la fidentia, la patientia y la perseuerantia: Cic., Inu. II 163). La uituperatio de 
En resumen, se observa que en particular la primera sentencia del sc. de diciembre del año 19 se estructura sobre el lugar común político y retórico de la muerte por la patria, que se hallaba en plena vigencia en el final de la República y en el Principado. Sobre la finalidad puramente laudatoria y consolatoria, se establece un juego de referencias con la Filípica 9, para sugerir el paralelo de Pisón-Antonio, enemigo del pueblo y concitador de las guerras civiles ${ }^{17}$.

\subsection{Temperantia Iulia Claudia}

Gracias a Tac. Ann. III 18, sabemos que SCPP 123-151 tuvo su origen en una propuesta de Valerio Mesalino, padre del homónimo cónsul del año 20 d.C. Se recogen en estas líneas alabanzas a miembros de la familia imperial por su actitud ejemplar después de la muerte de Germánico y durante el proceso de Pisón. Es constatable asimismo que existe una estrecha dependencia entre la sententia propuesta en el senado y la recogida en el decreto senatorial. Por tanto, habrán de manifestarse con claridad rasgos de elaboración oratoria ${ }^{18}$.

Si bien el análisis que sigue se concentra en 136-146, líneas dedicadas a la moderación de Agripina, Antonia y Livia, es necesario considerar en su conjunto toda la sententia de Mesalino que, una vez aprobada por el senado, fue recogida con la siguiente estructura:

(123-132) Elogio de Tiberio, como modelo de pietas y moderatio (125: tam aequalis

Pisón se refuerza en la exposición de sus actos en Siria. El decreto senatorial recuerda la actitud de Antonio en Phil. 9, al llamar a Pisón enemigo del pueblo romano e incitador de la guerra civil: v. 45-47. Se destaca así su crudelitas en 49-52 y la corrupción de la disciplina militar en 52-53. Por último, el lenguaje de Phil. 9.15 (Notetur etiam M. Antoni nefarium bellum gerentis scelerata audacia) recuerda significativamente a SCPP 12-15 (Senatum populumq. Romanum ante omnia dis immortalibus gratias agere,/ quod nefaris consilis Cn. Pisonis patris tranquillitatem praesentis status/r.p., quo melior optarinon pote $\left.{ }^{\lceil}\right\rceil$t, quo beneficio principis nostrifruicontigit,/ turbar ${ }^{\lceil}{ }^{\rceil}$passi non sunt) y 165-168. La referencia a los scelera Antonii es constante en las Filípicas, sobre todo en el tercer discurso, que relaciona sus scelera y la guerra civil: 3.5, 9, 33. El paralelo Pisón-Antonio debió de cundir entre la opinión pública, v. Tac., Ann. III 18.1.

17 Sobre el uso de la figura y de la terminología ciceroniana desde el comienzo del principado augústeo, R. Syme, The Roman Revolution, Oxford, 1939, p. 318ss.; J. Béranger, Principatus, Ginebra, 1973, pp. 117-134 y H. Bellen, Gymnasium 92, 1985, pp. 161-189.

18 W. Eck, A. Caballos y F. Fernández (n. 1), p. 234ss.; W.D. Lebek, «Das Senatus Consultum de Cn. Pisone Patre und Tacitus», ZPE 128, 1999, p. 184ss. 
doloris).

(132-136) Elogio de Julia Augusta y de Druso César: se destacan la moderación, la imitación de la justicia de Tiberio y la pietas acompañada de equidad (135: aequitas in seruandis integris iudicis suis).

(136-151) Elogio de los parientes directos a Germánico:

136-139 Elogio de la viuda Agripina: la unica concordia con Germánico y la numerosa progenie, prueba de su mutuo amor:

... ceterorum quoq(ue) contingentium Germanicum/ Caesarem necessitudine magnopere probare: Agrippinae, quam senatui memoriam/ diui Aug(usti), qu<o >i fuisset probatissuma, et uiri Germanici, cum quo unica concordia uixsis/set, et tot pignora edita partu felicissumo eorum, qui superessent, commendare.

Asimismo (el senado) apreciaba encarecidamente (la moderación ${ }^{19}$ ) de los demás que se hallaban en una relación de parentesco con Germánico César: (la) de Agripina, a la cual -según opinión del senado- elogiaban la memoria del divino Augusto, de quien había sido muy apreciada, y la de su esposo Germánico, con el que había vivido en excepcional concordia, y tantas prendas de su amor dadas por el felicísimo nacimiento de aquellos que habían sobrevivido.

140-146 Elogio de Antonia, su madre, y de Livia, su hermana. Los motivos son el unum matrimonium con Druso y la fidelidad hacia sus familiares respectivamente ${ }^{20}$ : itemq(ue) Antoniae Germanici Caesaris matris, quae unum matrimonium Dru/si Germ(anici) patris experta sanctitate morum dignam se diuo Aug(usto) tam arta propin/quitate exhibuerit, et Liuiae sororis Germ(anici) Caesar(is), de qua optume et auia sua et/ socer idemq(ue) patruos, princeps noster, iudicare $<\mathrm{n}>\mathrm{t}$, quorum iudicis, etiam si non/ contingere $\{\mathrm{n}\} \mathrm{t}$ domum eorum, merito gloriari posset, nedum tam coniunctis necessitu/dinibus inligata femina, quarum aeq(ue) et $\operatorname{dolor}^{\lceil} \mathrm{e}^{\top} \mathrm{m}$ fidelissumum et in dolore/ moderatione $<\mathrm{m}>$ senatum probare; ...

E igualmente (la) de Antonia, madre de Germánico César, que conociendo un único matrimonio con Druso Germánico padre, se mostró digna por su probidad de costumbres de tan estrecha afinidad con el divino Augusto, y la de Livia, hermana de Germánico César, a la que tenían en la mayor estima tanto su abuela, como su suegro, e igualmente su tío paterno, nuestro príncipe, por cuyas opiniones, aunque no estuviese emparentada con su familia, podía gloriarse merecidamente y con mayor motivo siendo una mujer unida por tan estrechos parentescos. De ellas el senado alababa por igual el dolor fidelísimo y en el dolor la moderación.

De estas tres feminae, se destaca su dolor regido por la moderación, es por tanto una moderatio privada, que no se refiere directamente a su actuación en

19 Efectivamente, como apunta Lebek (ibíd., p. 191, n. 30), hay que aceptar de modo necesario un anacoluto en los genitivos de las líneas (135), 137, 140 y 142. En mi opinión, hay que suponer un sustantivo moderationem elidido o supuesto (desde la línea 133), del que dependen los genitivos ceterorum, Agrippinae, Antonia y Liuiae. El inconveniente de la lejanía de moderationem en 133 quedaría así salvado.

20 Salvo en la línea 143 (iudicare $<n>t$ pro iudicaret), sigo la primera edición. 
el juicio, como era el caso de los elogios anteriores. El elogio se debe referir necesariamente a las tres, incluida Agripina, dada la unidad del párrafo.

(146-151) Elogio de sus hijos y de su hermano Tiberio Claudio: su dolor no ha excedido la justa medida, hecho que se debe sin duda a la educación recibida de Tiberio y Julia.

La propuesta de Mesalino es una sentencia secundaria, introducida una vez que ya había sido aprobado el cuerpo principal del senadoconsulto, técnicamente de carácter judicial. El motivo en el que el senador fundamenta su alabanza de la familia imperial es la moderatio de cada uno de sus miembros. Los paralelos de este tipo de alabanza que se hallan en los panegíricos ${ }^{21}$ y el architex to de la preceptiva epidíctica acerca de la moderatio, como parte de la temperantia en las clasificaciones per species uirtutum, no indican necesariamente que SCPP 136-146 responda a un patrón retórico específico. Propiamente lo que prueba una influencia cercana de la preceptiva son las amplificationes de Mesalino acerca de la moderatio de Agripina, Antonia y Livia. El senador alaba su moderatio de la domus en el luto por Germánico y durante el proceso de Pisón y añade específicamente para estas tres feminae la fidelidad matrimonial (y la fecunditas en el caso de Agripina), lo cual tenía un uso extensivo en la literatura encomiástica y consolatoria, como manifestaciones de la moderatio ${ }^{22}$.

21 Así por ejemplo, Plin., Pan. 83 alaba la moderatio de Plotina. Es ésta una moderatio privada, como la de Agripina, Antonia y Livila en el sc. de Pisón, con la diferencia de que se refiere sólo indirectamente a la pudicitia (Quid enim illa sanctius, quid antiquius? - Cfr. Plotinam sanctissimam feminam en Ep. IX 28,1 y también la laudatio funebris pronunciada por Trajano,

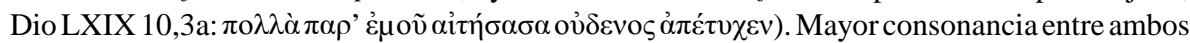
testimonios adquiere el hecho de que la moderatio sea imitación del gobernante (SCPP, 133 y 149150; Plin. Pan. 83,6-8), que se convierte así en verdadero objeto de la laudatio. Sobre la retórica del Panegyricus, que no se atiene rigurosamente a los preceptos, pero que manifiesta un uso de los tópicos laudatorios, v. P. Fedeli, «Il 'Panegirico' di Plinio nella critica moderna», en ANRW, II 33.1 (1989), pp. 411-416.

22 La moderatio en relación con la temperantia es tratada como tópico en Part. 76: quae uero moderandis cupiditatibus regendisque animi motibus laudatur, eius est munus in agendo; cui temperantiae nomen est. En obras filosóficas moderatio y temperantia son aspectos diversos de

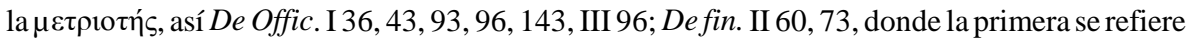
a la conducta externa y la segunda a los principios. En III 116 son manifestaciones diversas de una misma virtud. Menandro el Retórico fundamenta precisamente la laudatio de la temperantia en

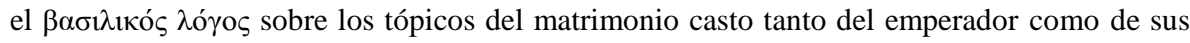
antepasados -la mención de la esposa es por tanto necesaria-, y de la moderación en espectáculos 
Junto a un primer architexto retórico tradicional, desempeña además un importante papel el referente de los modelos de la familia imperial, que se han quedado fijados precisamente en este periodo en la propaganda oficial como manifestación de la "nueva era" ${ }^{23}$. Dentro de esta misma corriente, la literatura encomiástica y consolatoria ${ }^{24}$ participan extensivamente de la temática y en particular retorizan como exemplum de pudicitia la fidelidad mutua de Druso y su esposa ${ }^{25}$.

En consecuencia, la asociación pudicitia-moderatio en SCPP 133-146 indica no sólo un lugar común de esta virtud referida a los miembros de la familia $^{26}$, sino también la elaboración oratoria de estas líneas. Expresado de otro modo, Valerio Mesalino utiliza en el discurso de su propuesta un tópico recibido en la educación retórica, que le permite además hacer una alabanza de

y festivales: Men. Rh. 376; W. Kierdorf, Laudatio Funebris. Interpretationen und Untersuchungen zur Entwicklung der römischen Leichenrede, Meisenheim am Glan, 1980, pp. 77ss.; L. Pernot, La rhétorique de l'éloge dans le monde gréco-romain, París 1993, pp. 162ss.; M. Mause, Die Darstellung des Kaisers in der lateinischen Panegyrik, Wiesbaden, 1994, pp. 122ss. El tópico es recurrente en las laudationes fúnebres que tengan como destinatario una mujer, $\mathrm{v}$. p.ej.: ILS 8393 I,30ss.; CIL VI 10230,27ss.; CIL XIV 3579, 14 y 21-30. Cfr. los paralelos de SCPP 136-146 con Tac., Ann. XII 6, que es también un discurso estructurado según la moderatio.

23 P. Zanker, Augustus und die Macht der Bilder, Múnich, 1990, pp. 162 y 177ss.

24 V. por ejemplo, Prop. IV 11,33-36, 45-46 y 61-64; Stat., Silu. III 3,120-123; V 145-50.

25 Suet. Aug. 34,1; Plin. NH VII 19; Val. Max. IV 3,3: Antonia quoque, femina laudibus uirilemfamiliae suae claritatem supergressa, amorem mariti egregiafide pensauit, quae post eius excessum forma <et> aetate florens conuictum socrus pro coniugio habuit, in eodemque toro alterius adulescentiae uigor extinctus est, alterius uiduitatis experientia consenuit; Jos. AJXVIII

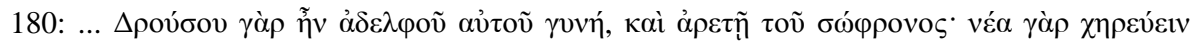

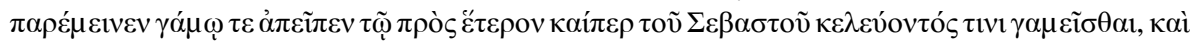

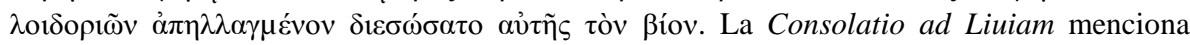
extensamente la concordia matrimonial de Druso y Antonia y la pudicitia de Livia: 299-306: Quid referam de te, dignissima coniuge Druso/ Atque eadem Drusi digna parente nurus?/ Par bene compositum: iunenum fortissimus alter,/ Altera tam forti mutua cura uiro./ Femina tu princeps, tu filia Caesaris illi/ Nec minor es magni coniuge uisa Iouis./ Tu concessus amor, tu solus et ultimus illi,/Tu requies fesso grata laboris eras; y 41-44: Quid tibi nunc mores prosunt actumque pudicel Omne aeuum et tanto tam placuisse uiro?/ Quidque pudicitia tantum cumulasse bonorum,/ Ultima sit laudes inter ut illa tuas?

26 La moderatio de Germánico en su actuación en Oriente en oposición a la feritas morum de Pisón se destaca en SCPP 25 y 167 y la de Tiberio posiblemente también en TS I 5: ... is (sc. Tiberius), adsu[e]ta sibi [moderatione, exomnibus iis]/ honoribus, quos habendos esse censebat senatus, legeret eo $[$ s quos... 
Germánico y Tiberio como trasfondo de la moderatio familiar ${ }^{27}$. El senado asume la propuesta y la recoge en la redacción final dentro del conjunto de las demás sentencias. Con ello queda desdibujada la unidad interna temática de la intervención de Mesalino y puede parecer que las virtudes atribuidas por el senado no respondan a una estructura conceptual coherente. Es cierto que la moderatio-temperantia en SCPP 133-146 no es parte de un canon completable con otras virtudes mencionadas a lo largo del senadoconsulto. Ahora bien, es preciso tener también en cuenta que en la adscripción de cualidades virtuosas a la familia Julio-Claudia a lo largo de los textos senatoriales han influido modelos retóricos, y no únicamente el nuevo sentido que adquieren las uirtutes oficiales en el Principado ${ }^{28}$.

\subsection{Inlustre ingenium Germanici Caesaris}

A diferencia del decreto sobre el arco en Roma, algunas propuestas honoríficas del año 19 no se han conservado más que en la ley comicial subsiguiente, de modo que no reflejarían una impronta retórica, dado que la versión definitiva de la rogatio reelaboró las sentencias más profundamente que el senadoconsulto. No obstante, la técnica oratoria intervino también en la inuentio y, en consecuencia, el contenido de los parágrafos de la ley puede mostrar ocasional e indirectamente una elaboración oratoria en las sentencias originarias. Uno de estos parágrafos puede servir de ejemplo.

En consideración a sus cualidades ${ }^{29}$, Druso y su hijo Germánico fueron honrados por el senado con sendos retratos entre los de los oradores, que se en-

27 La intervención retórica de estas líneas se aprecia en la estructura temática, evidentemente no en el estilo, v. W.D. Lebek, ZPE 128, 1999, p. 198: «Man erkennt deutlich, daß Messallinus, obwohl er an der Endredaktion des S.C. de Pis. patre mitgewirkt hat, keine stilistische Glättung versucht hat».

${ }_{28}$ Los estudios han estado por ahora centrados sólo en este segundo aspecto, D.S. Potter, «Political Theory in the Senatus consultum de Cn. Pisone patre», AJPh 120, 1999, pp. 70-71.

29 Sobre las cualidades de Germánico para la oratoria: aparte del ya mencionado Tac., Ann. II 83,3, Suet., Cal. 3,1-2; Cl. 11,2; Ovid., Fasti I 19-24; Pont. IV 8,6-7; Plin., NH VIII 42; E.R. Parker, «Education of Heirs in Julio-Claudian Family», AJP 67, 1946, pp. 38-39. Sobre este honor póstumo de Germánico, v. S. Weinstock, «The Image and Chair of Germanicus», JRS 47, 1957, pp. 144-154, M. Corbier, «De la Maison d'Hortensius à la curia sur le Palatin», MEFRA 104, 1992, pp. 871-916, Ead., «À propos de la tabula Siarensis: le sénat, Germanicus et la domus Augusta», en J. González (ed.), Roma y las prouincias: realidad administratiua e ideología imperial, Madrid, 1994, pp. 39-83 y Tabula Siarensis (n. 1), p. 270ss. 
contraban en la Biblioteca del templo de Apolo en el Palatino. Reflejo de esta propuesta en el senadoconsulto original es Tac. Ann. II 83.3, donde Tiberio modera el exceso de la propuesta: cum censeretur clipeus auro et magnitudine insignis inter auctores eloquentiae, adse <ue >rauit Tiberius solitum paremque ceteris dicaturum: neque enim eloquentiam fortuna discerni et satis inlustre, si ueteres inter scriptores haberetur.

La sentencia, modificada según el parecer del princeps, queda reflejada en la ley, TS IIc, $13-17=\mathrm{TH}, 1-4^{30}$ :

\footnotetext{
Vtique in Palatio [in porticu quae est ad Apollinis in eo templo in quo senatus]/ haber ${ }^{\lceil}{ }^{\top}$ solet in[ter ima|gines uirorum in ${ }^{\lceil} 1^{\top} \mathrm{us}^{\lceil} \mathrm{t}^{\top}$ ris ingeni Germanici Caesa] $/{ }^{15}$ ris et Drusi Ger[manici patris eius naturalis fratris|Ti(beri) Caesaris $\operatorname{Aug}($ usti) $] /$ qui $\{\mathrm{m}\}$ ipse quoqu[e $\left.\mathrm{f}^{\lceil} \mathrm{a}\right\rceil$ cundi ingeni fuit imagines ponantur supra capita]/ columnarum [eius fas|tigi quo simulacrum Apollinis tegitur.]

Y que en el Palatino, en el pórtico que está junto al templo de Apolo, en el templo en el que suele reunirse el senado, se coloquen [entre] los retratos de los varones de elocuente talento ${ }^{31}$, retratos de Germánico César y de Druso Germánico su padre natural [y hermano] de Tiberio César Augusto que fue también de facundo talento, sobre los capiteles de las columnas [del] frontón con el que se cubre la imagen de Apolo.
}

El honor se fundamenta en la memoria, como revivencia visual del difunto. Pero, de acuerdo con los datos conservados, no hay una tradición específica para las honras póstumas a la elocuencia: a diferencia de otros honores concedidos, en este caso falta el punto de referencia de uno semejante decretado para Augusto, Druso o Gayo y Julio Césares. Fundamento de esta decisión pueden ser las connotaciones políticas que adquirirían los retratos en el complejo augústeo del Palatino. Sin embargo, no se puede perder de vista que la propuesta originaria fue presentada en una intervención senatorial. Ésta adopta modos demostrativos, que se adaptan al deseo de mostrar la propia lealtad hacia la familia imperial. El tema elegido es un tópico en íntima relación con el tenor ejemplar de vida y con la educación del personaje laudado: la aptitud para las artes liberales y su gusto por las letras ${ }^{32}$.

30 Texto según Tabula Siarenis (n. 1); se indican mediante | los cortes de línea de la tabula Hebana.

31 Inlustris ha de referirse necesariamente a las cualidades oratorias, aceptando la hipótesis de Weinstock para corregir $f^{\lceil} a^{\rceil}$cundi en la línea 16; sobre esta problemática, v. Tabula Siarenis (n. 1), pp. 277-278.

32 Ésta es el segundo apartado de las laudationes póstumas que siguen una sucesión cronológica: v. Cic., De Orat. II 46; Quint. III 7,15; Men. Rhet. III 413 y 420 . El tópico es 
Cercano en lenguaje a la ley Valeria Aurelia ${ }^{33}$, Cons. Liu. 261-262 (uictricesque manus facundaque principis ora / pectoraque, ingenii magna capaxque domus) confirma un referente extratextual retórico para ambos textos. A diferencia de la rogatio, en el Epicedion Drusi se separan la excelencia oratoria (facunda... ora) del talento en general, que es fundamento de la facundia de toda la domus (pectoraque, ingenii... domus). La asociación entre padre e hijo viene dada en este punto por el propio sentido de ingenium, como talento heredable del que participa toda la familia ${ }^{34}$. Así, como en el caso de la alabanza a la moderatio en el senadoconsulto de Pisón, el honor atribuido a Germánico es utilizado como medio para referirse al conjunto de la domus imperial.

La reconstrucción del discurso pronunciado realmente es a todas luces imposible, dado que no se conserva la parte correspondiente en el senadoconsulto. Ahora bien, sobre la base de que la intervención senatorial estaba elaborada temática y estructuralmente según pautas retóricas, se puede suponer que ésta comenzaría con una cláusula causal expandida introducida por cum (cum Germanicus...) en la que se explicaría que había sido eximio orador, como parte de su excepcional educación y talento heredado (facundi ingenii...), hecho que compartía con su padre (Drusus Germanicus pater eius naturalis frater Tiberi Caesaris Augusti) y por tanto el senador proponía colocar sus retratos entre los

explotado también en el subgénero consolatorio: cfr. Cons. Liu. 261-262 y Stat., Silu. II 1,113-119 (sobre las cualidades poéticas en el marco del elogio a la infancia y educación) y V 3,107-108. Es la tradición griega la que principalmente trata este aspecto y resulta difícil encontrar tanto en la teoría como en las laudationes latinas menciones de la educación del personaje. A partir de época imperial aparecen referencias en el ámbito latino al gusto por las artes liberales o al carácter sociable. Probablemente los manuales retóricos no responderían a una tradición unitaria y no todos considerarían este elemento como unidad por sí misma: W. Kierdorf, Laudatio Funebris (n. 22), pp. 68-71. La sociabilidad de Germánico es prácticamente tópica en la tradición: cfr. Tac., Ann. II 59,1; Dio LVI 24.7; LVII 18,6-8. Sobre el papel de esta unidad temática en los Panegíricos, v. L. Pernot, La rhétorique de l'éloge... (n. 22), pp. 161ss. y 726ss. y M. Mause, Darstellung (n. 22), p. 92 ss.

33 Lo cual serviría como prueba adicional para corregir $f^{\lceil} a^{\rceil}$cundi.

34 Este es el sentido de las referencias al talento de Valerio Mesalino en Ov. Ex P. II 2,51: uiuit enim in uobis facundi lingua parentis y Tr. IV 4,3-5: cuius inest animo patri candoris imago... cuius in ingenio est patriaefacundia linguae, que se corresponden con Tac. Ann. III 34,2: Valerius Messalinus, cuis parens Messala ineratque imago paternae facundiae. Tanto si imago tiene sentido de totalidad como si lo tiene de parcialidad (J. Ginsburg, «In maiores certamina: Past and Present in the Annals», en T.J. Luce y A.J. Woodman (eds.), Tacitus and the Tacitean Tradition, Princeton, 1993, pp. 86ss.), Tácito se está refieriendo al talento retórico "compartido" por padre e hijo. 
de los oradores famosos (censeo uti... inter imagines uirorum inlustris ingeni... imagines ponantur).

En síntesis, la elección de honores recogida en la tabula Siarensis no se lleva a cabo únicamente según los conceptos de memoria y luctus y según la tradición de los anteriores decretos de honores póstumos. La temática de ciertos honores indica además que el documento es elaborado sobre intervenciones con marcado tono eulogístico y cuyo contenido dependía, por tanto, de tópicos que provenían de la práctica epidíctica.

\section{Epideixis y consensus}

Tanto uno como otro senadoconsulto incluye una fórmula final poco usual, que indica que las propuestas fueron aprobadas per relationem: TS IIb 30-31: $H($ oc) s(enatus) c(onsultum) per relatio/nem secundam factum est unum; SCPP 173: Hoc s(enatus) c(onsultum) factum est per relationem solum. La expresión indica que a lo largo de las sesiones hubo unanimidad y que los decretos fueron aprobados sin necesidad de recurrir a una votación pormenorizada ${ }^{35}$. En estos casos, el senadoconsulto es denominado oficialmente per discessionem (es decir, por voto inmediato) y una vez en Aulo Gelio per relationem, con una formulación que aporta un importante matiz para la comprensión del tono de estos documentos ${ }^{36}$ :

Gell. XIV 7,9: senatusque consultum fieri duobus modis, aut per discessionem, si consentiretur, aut si res dubia esset, per singulorum sententias exquisitas ... $\|$ ibid. 12-13: sed quod ait senatus consultum duobus modis fieri solere, aut conquisitis sententiis aut per discessionem, parum conuenire uidetur cum eo quod Ateius Capito ... scriptum reliquit. Nam ... Tuberonem dicere ait nullum senatus consultum fieri posse non discessione facta, quia in omnibus senatus consultis, etiam in iis quae per relationem fierent, discessio esset necessaria ...

35 Según interpretación de C. Nicolet, «La tabula Siarensis, la lex de imperio Vespasiani et le jus relationis de l'empereur au sénat», MEFRA 100, 1988, pp. 827-866. Vid. asimismo acerca del procedimiento per discessionem, A. O’Brien Moore, «Senatus consultum», en RE Suppl. VI (1935), col. 803; R.J.A. Talbert, The Senate of Imperial Rome, Princeton, 1984, pp. 279-285; M. Bonnefond-Coudry, Le Senat de la république romaine: de la Guerre d'Hannibal à Auguste: pratiques déliberatives et prise de décision, Roma, 1989, pp. 482-487 y W.D. Lebek, ZPE 90, 1992, p. 67ss.

36 Un paralelo en Gelio de esta oposición entre el consensus y res dubia se puede encontrar en III 3,3: quoniam dubiosae non erant, set consensu omnium... 
El primero de los dos pasajes menciona que si la materia es cierta y no ofrece duda, habrá unanimidad en el plano del procedimiento legal con manifestaciones en el modo de aprobación de los textos. La mención del carácter dudoso de la materia nos remite al problema de la definición de los géneros oratorios.

La tradición retórica, que estaría presente en la educación tanto de los redactores como de los oyentes de los decretos de los años 19 y 20, no era del todo unitaria, pero la división tripartita atribuida a Aristóteles es dominante ${ }^{37}$. Quintiliano añade a la definición el criterio del carácter dubium o certum de la materia. Esta formulación, que en principio sería aportación originaria, es consecuencia de la división griega entre árbitro y espectador, es decir, entre una consideración activa o pasiva de la actitud del oyente: si la materia era un asunto todavía por decidir (dubium), el discurso se adscribía al genus iudiciale o al deliberatiuum, dependiendo de su carácter pasado o futuro respectivamente; en cambio, si el asunto era algo comúnmente aceptado (certum), al genus demonstratiuum ${ }^{38}$.

Quintiliano mismo, sin embargo, notaba que la división no era del todo convincente, y en Inst. III 4,16 concluye del siguiente modo: ... celeri magis ac rutunda usi distributione quam uera. Stant enim quodam modo mutuis auxiliis omnia ${ }^{39}$. La clasificación es una definición negativa, que ya estaba presente de forma diferente en la tradición griega. Propiamente tanto Isócrates,

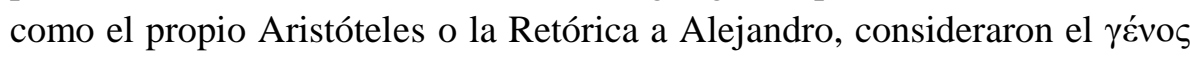

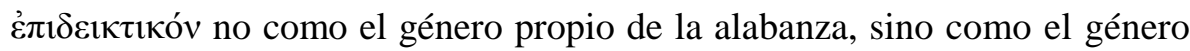

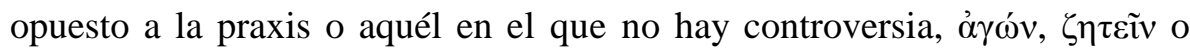
$\dot{\alpha} \mu \varphi \iota \sigma \beta \eta \tau \varepsilon \tilde{i}^{40}$. Así, será epidíctico todo texto oral o escrito que no tenga como

37 Entre otros, Arist., Rh. 1358a,36ss.; Cic., Part. 10; Top. 91-92 y Quint. II 4,8; 7,3.

38 V. tambien Cic., Part. 71: Non enim dubia firmantur sed ea quae certa aut pro certis posita sunt augentur.

39 V. también Cic., De orat. II 43 y Orat. 42.

40 Sobre el problema de la inclusión del tercer género y la definición de lo epidíctico, v. entre otros D.A.G. Hinks, «Tria genera causarum», $C Q$ 30, 1936, pp. 170-176; V. Buchheit, Untersuchungen zur Theorie des Genos Epideiktikon von Gorgias bis Aristoteles, Múnich, 1960, pp. 120-128; A. Hellwig, Untersuchungen zur Theorie der Rhetorik bei Platon und Aristoteles, Gotinga, 1973, pp. 152ss.; L. Pernot, La rhétorique de l'éloge... (n. 22), pp. 32ss. y 71ss.; G.A. Kennedy, «The Genres of Rhetoric», en S.E. Porter (ed.), Handbook of Classical Rhetoric in the Hellenistic Period (330 B.C.-A.D. 400), Leiden, 1997, pp. 43-50; Mª I. Gómez Santamaría, «Notas sobre el genus demonstrativum en Quintiliano», en T. Albadalejo, E. del Río y J.A. Caballero 
propósito la persuasión, sino realzar lo ya sabido o admitido, lo cual podrá ser expresado no necesariamente a través de la alabanza.

En consecuencia, lo esencial del tercer género es el consensus, la cohesión social, que como contenido el senado procura transmitir insistentemente en los senadoconsultos de Germánico y de Gneo Pisón. La cuestión adquiere, por tanto, una nueva perspectiva en relación con la situación política del momentoto. Lo determinante de cara al género que éstos adoptaron no era la materia, sino la situación de excepción social de esos dos años ${ }^{42}$ y la necesaria influencia de los contenidos propagandísticos del principado augústeo ${ }^{43}$.

El consensus en el duelo popular por Germánico desemboca en un iustitium. En un segundo plano de elaboración, esta situación excepcional considerada como acontecimiento es retorizada en un nuevo tópico de la laudatio, al que se recurre en las descripciones del funeral ${ }^{44}$ : la extraordinaria concordia que

(eds.), Quintiliano: historia y actualidad de la retórica, II, Logroño, 1998, pp. 907ss. y T. Zinsmaier, «Epideiktik zwischen Affirmation und Artistik», en J. Kopperschmidt y H. Schanze (eds.), Fest und Festrhetorik, Múnich, 1999, pp. 375ss. El carácter esencial de la ausencia de ả $\gamma \omega \dot{v} v$ para definir el género sigue estando presente en Men. Rhet. I 331,17-18.

$41 \quad T S$ IIb 23 y $S C P P 155$.

42 La desaparición del joven príncipe, en el que residía para gran parte de la opinión pública la salus de la patria, causa un colapso en la actividad política y social. En el ambiente de duelo espontáneo, la insistencia en la laus del difunto sería un elemento natural y, por tanto, explicable sin una intervención retórica deliberada. Pero la cuidadosa elaboración de ambos textos indica que se trata de respuestas oficiales, que pueden coincidir eventualmente con las manifestaciones populares, pero que no participan de esa espontaneidad.

43 El consensus dentro del ideario político del principado refrenda la legitimidad del régimen, tal como se expresa en las Res gestae, puesto que todos los órdenes sociales en espontánea unanimidad habrían puesto en manos de Augusto la res publica: v. A. von Premerstein, Vom Werden und Wesen des Prinzipats, Múnich, 1937, p. 62ss.; C. Nicolet, L'ordre équestre à l'époque republicaine, París, 1966, pp. 633ss.; A. Wallace-Hadrill, «Civilis Princeps: Between Citizen and King», JRS 72, 1982, pp. 32-48; D. Kienast, Augustus. Prinzeps und Monarch ${ }^{2}$, Darmstadt, 1999, pp. 67ss. y 80ss. y W. Eck, A. Caballos y F. Fernández, Das senatus consultum... (n. 1), p. 298ss. Sobre la relación entre la crisis de la oratoria, el auge de la epidíctica y el ocaso de la vida política en la conciencia colectiva de los siglos I y II d.C., v. Tac., Dial. 36ss.; Ps.-Long., De sublim. 44; otros testimonios en E. Norden, Die antike Kunstprosa, Leipzig, 1898, pp. 245-248. Cfr. además R. Güngerich, Kommentar zum Dialogus des Tacitus, Gotinga, 1980, pp. 201ss., K. Heldmann, Antike Theorien über Entwicklung und Verfall der Redekunst, Múnich, 1982, pp. 255ss y G.W. Williams, Change and Decline. Roman Literature in the Early Empire, Berkeley-Los AngelesLondres, 1978, pp. 6ss.

44 CIL VI 40360,4-5: mortem eius iustitio per con[sules indicto]/omnes luxerunt (elogium 
suscitó su duelo honra asimismo al difunto. No podía extrañar, por tanto, que la Consolatio ad Liuiam (201-204) utilizara este filón temático al describir el funeral del padre de Germánico:

Omnibus idem oculi, par est concordia flendi:

Funeris exequiis adsumus omnis eques;

Omnis adest aetas, maerent iuuenesque senesque,

Ausoniae matres Ausoniaeque nurus.

de Lucio César en el Mausoleo de Augusto); Decretum Pisanum II,14ss.: nondum quieto luctu, quem ex deces $/ /^{15} s u$ [L. C]aesaris fratris eius... colonia uniuersa susceperat, renouasset multiplicassetquel ma[er]orem omnium singulorum uniuersorumque, ob eas res uniuersi decu/rio[ne] s colonique; CIL VI 10230,17: ... post decessum consensu ciuium laudaretur (época augústea); Cons. Liu. 294: inuenit tota maeror in Vrbe locum; (cfr. también Stat. Silu. II 1,175ss.

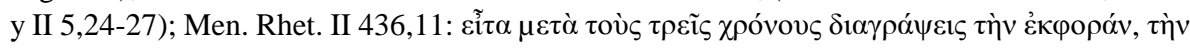

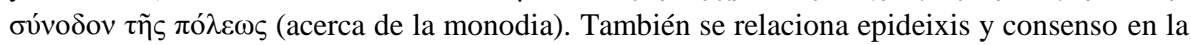
reacción popular ante la actuación de Octaviano: Cic. Ad Brut. V 2: di immortales! qui ille nuntius, quae illae litterae, quae laetitia senatus, quae alacritas ciuitatis erat! nihil umquam uidi tam omnium consensione laudatum. 